\title{
Groundwater fluoride as a geochemical marker in the etiology of chronic kidney disease of unknown origin in Sri Lanka
}

\author{
C.B. Dissanayake and Rohana Chandrajith*
}

Department of Geology, Faculty of Science, University of Peradeniya, Peradeniya, Sri Lanka

Received: 10/03/2017; Accepted:12/05/2017

\begin{abstract}
The correlation of chronic kidney diseases of unknown etiology $(\mathrm{CKDu})$ in some dry zone areas of Sri Lanka has led to several research investigations into the association of groundwater fluoride with chronic kidney diseases. Environment related kidney diseases in the tropics are clearly multi-factorial with drinking water expected to play a major role in addition to diet, heat stress and severe dehydration. The geochemistry of groundwater in such regions is marked by the presence of fluoride in significant quantities and is receiving increasing attention as a major risk factor in the prevalence of the chronic kidney disease in view of its geographic distribution pattern similar to that of the CKDu, nephrotoxicity and its very high reactivity with other substances. The dual cytoprotective and cytotoxic nature of fluoride depending on the dose and its competitive interactions with $\mathrm{Na}, \mathrm{Ca}$ and $\mathrm{Mg}$ has raised some interesting possibilities for $\mathrm{Mg}$ to act as a protective agent for $\mathrm{CKDu}$. This may be applicable, in general, to tropical arid regions with high amounts of $\mathrm{Na}, \mathrm{Ca}, \mathrm{Mg}$ and $\mathrm{F}$ in the groundwater. A case study from such regions in Sri Lanka shows that Mg-rich groundwater in the hard water terrains points to a lesser CKDu prevalence. This is indicative of a protective role for $\mathrm{Mg}$ against heart ailments caused by CKDu and more detailed investigations on the mechanisms of geo-biochemical interactions of $\mathrm{F}, \mathrm{Na}, \mathrm{Ca}$ and $\mathrm{Mg}$ in the etiology of CKD are clearly warranted.
\end{abstract}

Keywords: cytotoxicity; dry zone; Sri Lanka; kidney diseases, fluoride; water hardness.

\section{INTRODUCTION}

Chronic kidney diseases (CKD) are prevalent in many parts of the world and it has now become a global health issue (El Nahas and Bello, 2005). Among the well-known causes for CKD are hypertension, diabetes and chronic glomeronephritis. However, it is now known, notably in tropical arid regions, that there could be other causes for CKD as shown by several studies in Sri Lanka where CKD of unknown etiology $(\mathrm{CKDu})$ has been discovered
(Athuraliya et al., 2011; Chandrajith et al., 2011a). Large populations in tropical arid regions, notably those intimately associated with agriculture and farming is mostly at risk (Jayatilake et al., 2013). A very important and noteworthy feature is that these farming communities consume groundwater as their drinking water and at the same time they suffer from severe dehydration, bearing in mind the long hours of work under extremely hot and humid conditions. While agrochemicals and fertilizers laden with heavy metals notably $\mathrm{Cd}$, $\mathrm{Pb}$ are implicated as causative agents of the CKD of "unknown etiology" in Sri Lanka, the geographic distribution of the disease clearly indicates that only some regions in the dry zone are affected while the wet zone is free of the disease (Figure 1). This is indicative of a unique and constantly changing hydrogeochemistry brought about perhaps by a significant climatic change within the last two decades. Further, the fact that the common causes such as hypertension and diabetes have been ruled out as the initiators of CKDu in these regions, a more geo-oriented natural cause associated with a critical set of chemical parameters unique to the geology and the hydrogeochemistry of the regions mostly in tropical countries is indicated. The first Hydro-geochemical Atlas of Sri Lanka was published by Dissanayake and Weerasooriya (1985) and one of their major findings was that high concentrations of groundwater fluoride were distributed in the dry zone and that the wet zone had minimal fluoride. This map was later updated by Chandrajith et al. (2012) and the disease pattern of the CKD of unknown etiology coincided with that of the fluoride rich regions. This fact had shown that groundwater fluoride could well be a risk factor in the etiology of the kidney disease. Based on the geographical distribution of ground-water fluoride in the dry zone of Sri Lanka, Dissanayake (2005) first suggested that ground-water fluoride and its 
interactions with other elements could be associated with CKDu in Sri Lanka. Studies from several other countries of the tropical belt have clearly shown the importance of groundwater fluoride as a major risk factor for kidney diseases (Bober et al., 2006; Chandrajith et al., 2011a; Chandrajith et al., 2011b; Chouhan and Flora, 2008). The geochemical significance of some diseases in tropical countries have been highlighted by Dissanayake and Chandrajith
(1999) and they have shown that some diseases such as dental and skeletal fluorosis, iodine deficiency disorders, selenium-related diseases among others could also be classified as diseases of "geochemical origin". The new discipline "Medical Geology" therefore is of particular importance to tropical countries where extremely large populations live intimately associated with the immediate physical environment with their unique geochemical characteristics.

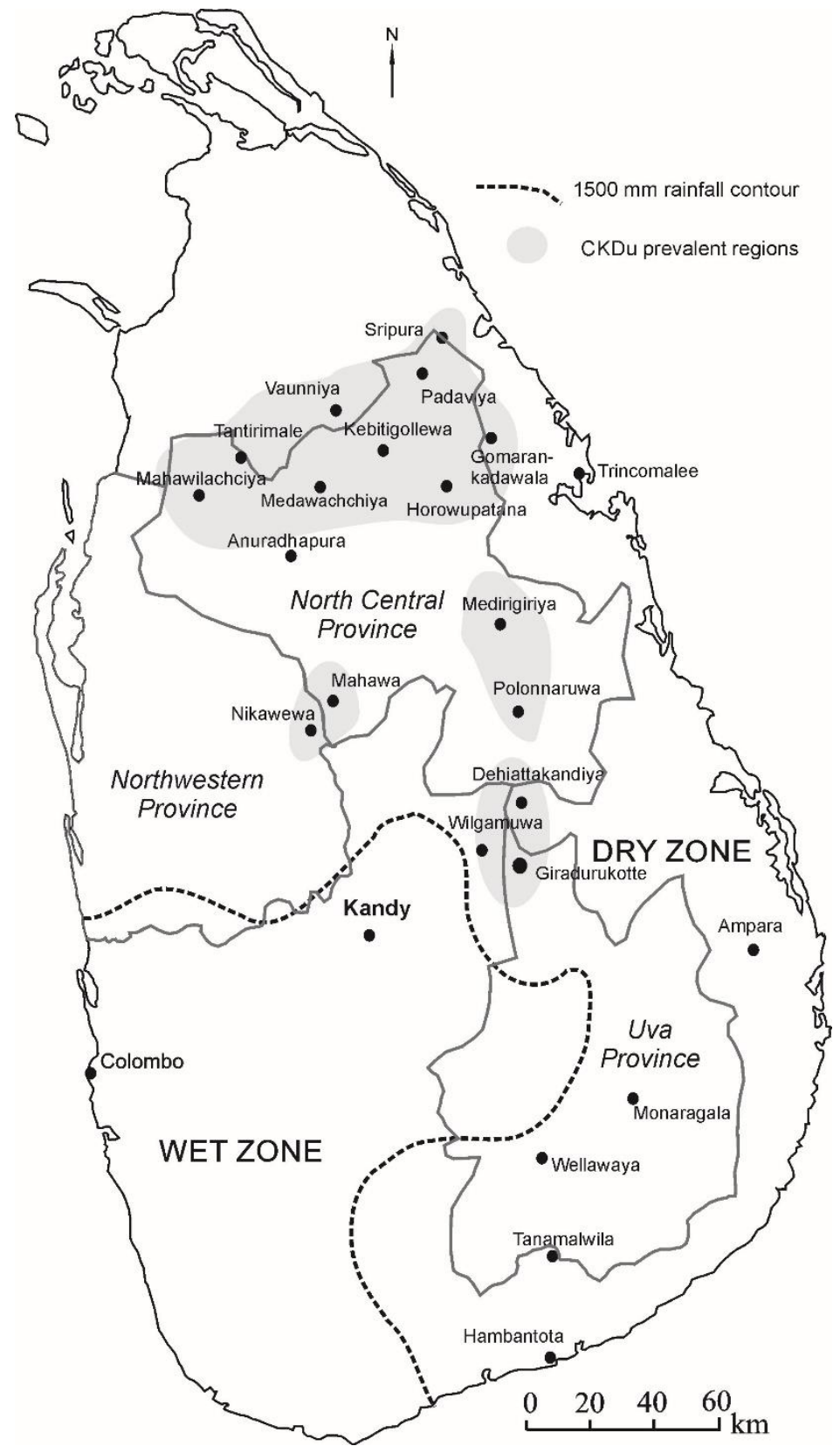

Figure 1: Distribution of Chronic Kidney Diseases with uncertain etiology (CKDu) in the dry zone of Sri Lanka. 


\section{GEOCHEMISTRY OF GROUNDWATER FLUORIDE}

It is a well-known fact that there is a strong relationship between fluoride geochemistry and the incidence of dental and skeletal fluorosis. While the essentiality of fluoride for human health is still being debated, its toxicity when present in excessive quantities has caused concern in many lands, particularly in dry arid zones where fluoride is found in groundwater in excessive quantities (Dissanayake and Chandrajith, 2007). Even though food is the main source of many trace elements entering the human body, much of the fluoride entering the body however, is from water (Dissanayake, 2005). The hydro-geochemistry of fluoride, particularly ground-water which is the main source of drinking water for millions of people in the tropical arid regions, is therefore of extreme importance.

Fluorine is the most electronegative element. Due to its very high reactivity, fluoride is a marked geochemical reactant in groundwater. Fluoride, as an ion, therefore does not act alone and its extreme reactivity makes it combine easily with metals such as $\mathrm{Cd}, \mathrm{Pb}, \mathrm{Hg}$ and also with metalloids such as arsenic, implicated by some authors (Jayasumana et al., 2013) as being the cause of the CKDu in Sri Lanka. Fluoride therefore, is an excellent geochemical carrier and a marker for a large number of possible causative agents. It is noteworthy that with the exception of the pineal gland, it is the kidney which accumulates fluoride most in the human body (Massy and Drüeke, 2012). The fact that the ionic radius of the fluoride ion $(0.133 \mathrm{~nm})$ is very similar to that of the hydroxyl ion $(\sim 0.110 \mathrm{~nm})$, makes fluoride an excellent aquaphile. Due to the replacement of hydroxide ion with fluoride ion, in dental and bone tissues it becomes geochemically and biochemically very active. The passage through the geo-bio barrier is ensured and once inside the human body, fluoride may affect several important enzymerelated metabolic functions. Fluoride crosses cell membranes by simple diffusion, enters soft tissues and causes their impairment (Chattopadhyay et al., 2011). A kidney when damaged for whatever reason will accumulate fluoride fast, thereby damaging the kidney even further. Farmers who are severely dehydrated may have damaged kidneys and the consumption of fluoride-rich water will almost certainly aggravate the CKD condition.

In addition, climate change has had a marked effect on the elevated concentrations of fluoride in groundwater in tropical countries over the last two decades. Recent investigations have shown that even within a few years, groundwater wells in the dry zone of Sri Lanka have shown a marked increase of fluoride changing from safe levels to "not recommended" levels (Chandrajith et al., 2012). The climate change and the consequent evapotranspiration have been very high in these tropical lands with the resulting elevations of fluoride, $\mathrm{Na}, \mathrm{Ca}$ and $\mathrm{Mg}$ in the groundwater. Jacks et al. (2005) studied the controls on the genesis of fluoride rich groundwaters in India where there was an increase in the incidence of dental and skeletal fluorosis with 62 million people at risk. They observed that fluoride concentrations are governed by adsorption equilibria and by fluorite stability. Evapotranspiration lead to a precipitation of calcite, a lowering of calcium activity and increase of $\mathrm{Na} / \mathrm{Ca}$ ratios which allowed an increase of fluoride levels in the solution. A significant feature was that due to irrigation and farming practices, there was an increase in the extent of the sodic soils which contributed to an increase of fluoride in groundwater and hence dental fluorosis (Jacks et $a l ., 2005)$. This is also applicable to the dry zone of Sri Lanka where due to the irrigation practices and water impounded in reservoirs, the lower reaches tend to be very rich in sodic soils thereby affecting the geochemical balance of groundwater fluoride, a fact which will have an impact on the kidney disease etiology. Therefore, the geochemical scenario of the arid tropical regions is of immense importance in that it changes constantly and rapidly while disease patterns also change accordingly. One cannot therefore arrive at too simplistic inferences by stating that fluoride and water hardness among others have been there for decades and that there had been no noticeable kidney diseases of uncertain etiology in Sri Lanka (Wimalawansa, 2016). The geochemical environment is in a continuous state of flux and subtle changes of geochemical ratios, particularly in groundwater therefore, could well have a major impact on changing patterns of health and disease. This fact has to be taken into cognizance by those who attempt to use total quantities, rather than chemical species and ratios of chemical species 
in nature for correlation with disease patterns. Unfortunately, many researchers investigating environment-related diseases do not consider the subtle temporal and spatial geochemical changes in the geo-environment.

\section{FLUORIDE AS A NEPHROTOXIN}

Fluoride has consistently been underestimated for its toxic effects mainly because of the proponents of water fluoridation emphasizing the supposed benefit of fluoride to dental health. While an optimum range may have benefits in dental health, excessive amounts will cause several negative physiological effects notably in the kidneys (Cittanova et al., 1996; Harinarayan et al., 2006). However, toxicity of fluoride was largely ignored due to its "good reputation" for preventing caries via topical application and in tooth pastes (Barbier et al., 2010). Even at low doses, fluoride could interact with cellular systems inducing oxidative stress and modulation of intracellular redox homeostasis among several others resulted in serious concerns about its toxicity (Cittanova et al., 1996).
Fluoride is more genotoxic at lower doses than at higher doses when ingested through drinking water (Podder et al., 2011). The determination of the exact dose of fluoride that is effective in the triggering of physiological imbalances and how other interactive chemical species such as $\mathrm{Na}^{+}$, $\mathrm{Ca}^{2+}$ and $\mathrm{Mg}^{2+}$ control the critical dose needs further extensive research. Zager and Iwata (1997) carried out some experiments in order to characterize some subcellular determinants of fluoride cytotoxicity and to determine whether sub-toxic fluoride exposure affects tubular cell vulnerability to superimposed ATP depletion and nephrotoxic attack. They concluded that;

(a) fluoride induces dose-dependent cytotoxicity in cultured human proximal tubular cells,

(b) this occurs via $\mathrm{Ca}^{2+}$ and phospholipase A2(PLA2) dependent mechanisms,

(c)partial cytosolic PLA2 depletion subsequently results and

(d) sub-toxic fluoride exposure can acutely increase cell resistance to further attack.

\section{Transport/Homeostasis}

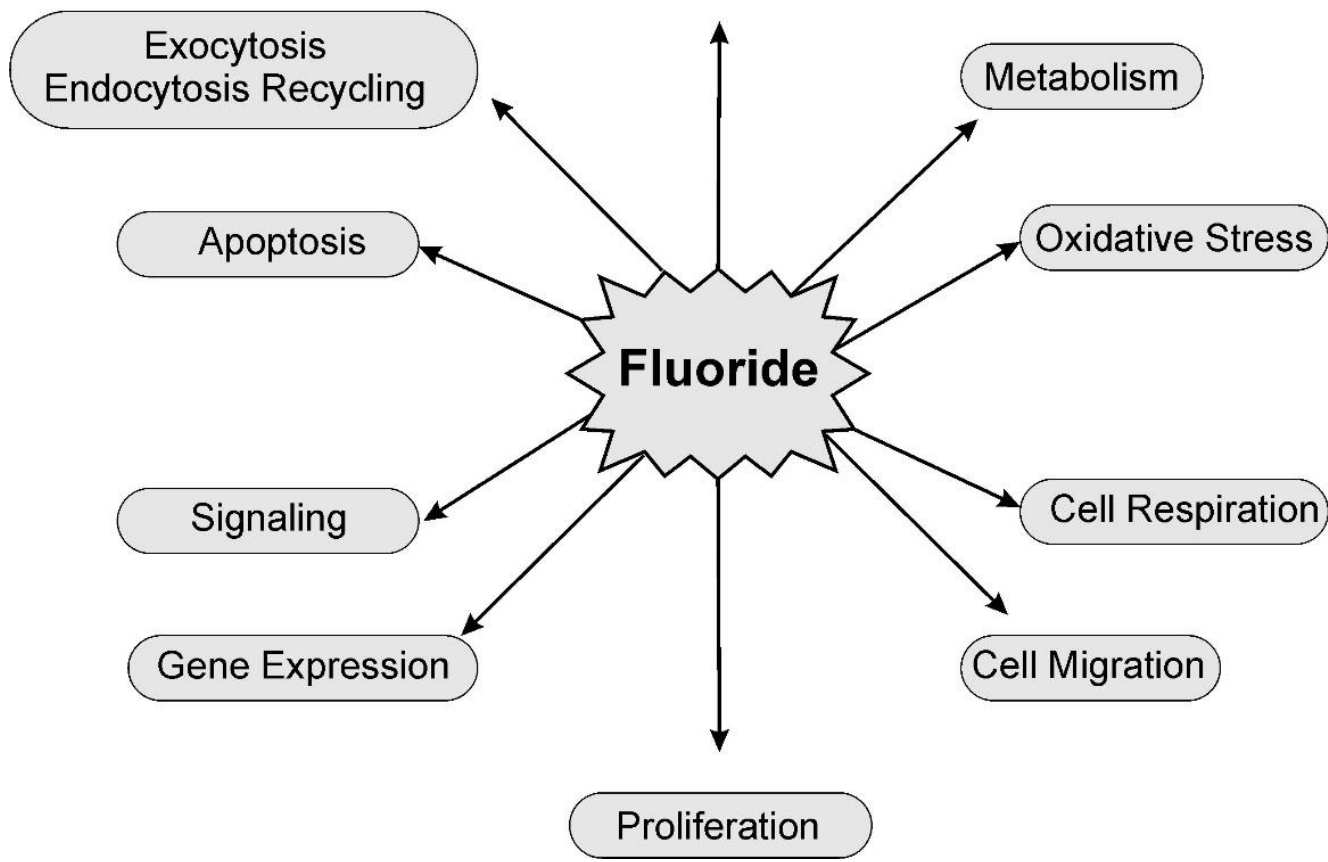

Figure 2: General scheme of the biological consequences of fluoride exposure on mammalian cells (modified after Barbier et al., 2010). 
Although dental fluorosis is the common symptom associated with high fluoride in drinking water, the liver and kidney functions can also be affected by high fluoride ( $>2 \mathrm{mg} / \mathrm{L})$ in children (Xiong et al., 2007). Moreover, coexposure of cadmium and fluoride could increase the liver and kidney damage compared with that exposed to individual ions alone as indicated using rat models (Zhang et al., 2013). These observations clearly highlight the need to place more emphasis on the critical doses and how these doses may be influenced by other factors in the physical environment, notably in groundwater. In the case of "CKD of unknown etiology" in the dry zone of Sri Lanka, the geochemical ratios of $\mathrm{F}^{-}$with $\mathrm{Ca}^{2+}, \mathrm{Mg}^{2+}$ and $\mathrm{Na}^{+}$ and their collective impact on the biochemical mechanisms leading to the disease may provide useful clues as to its actual cause. The effect of fluoride on a variety of cell functions becomes complex due to the fact that it is related to dose and concentration (hormesis effect) and fluoride has to be considered as a potent toxic compound in toxicology, epidemiology/ ecological research and in both fundamental and applied research (Barbier et al., 2010). The general scheme of the biological consequence of fluoride exposure on mammalian cell is illustrated in figure 2 .

\section{WATER HARDNESS AND FLUORIDE IN GROUNDWATER - ROLE OF MAGNESIUM}

One of the noteworthy features of the areas with CKDu in the dry zone of Sri Lanka, is the high prevalence of water with high hardness often exceeding $75 \mathrm{mg} / \mathrm{L}$ (Chandrajith et al., 2011b). The fact that these regions also superimpose, in many cases, on the high fluoride areas brings into focus a further complicating factor and possibly both water hardness and fluoride play a role in the etiology of the kidney disease. Hard water, by itself may not pose a serious threat to human health but its main components, $\mathrm{Ca}^{2+}$ and
$\mathrm{Mg}^{2+}$ may interact with other species to form complexes that may be of significance in health issues. When such water with high fluoride levels is consumed in large quantities, as in the case of the dry zone population of Sri Lanka, the interactions of $\mathrm{Ca}^{2+}, \mathrm{Mg}^{2+}, \mathrm{Na}^{+}$and $\mathrm{F}^{-}$may, in all probability, have an impact on the physiological functions. Numerous studies have shown an inverse relationship between drinking water magnesium level and heart diseases (Jiang et al., 2016; Knezović et al., 2014; Kousa, 2013; Leurs et al., 2010) although its effect on kidneys is still poorly understood. However, the increase of $\mathrm{Ca}^{2+} / \mathrm{Mg}^{2+}$ ratio in drinking water was attributed to the occurrence of urolithiasis (Yang et al., 2016). Dharma-Wardana et al. (2015) highlighted the importance of groundwater ionicity, emphasizing the suggestion that $\mathrm{F}^{-}$may contribute to the CKDu by its high rank in the Hofmeister Series for denaturing proteins of the kidney membrane. They also suggest that while the increase of hardness (below a threshold) correlates with good health, ionicity increases above a threshold would correlate with ill health. One of the main elements present in hard water is magnesium. While calcium has received great attention in issues pertaining to health and disease, notably the heart, magnesium however has not been considered adequately in medical research. Magnesium is the activator of more than 300 enzymes (Gröber, 2009), while fluoride is known to act as an inhibitor. Their geochemical and subsequent biochemical interactions are of importance in tracing the pathways to kidney disease. A further complication is the fact that some enzymes are known to be activated by fluoride (Strochkova and Zhavoronkov, 1983). The interference of $\mathrm{F}^{-}$ with the biological activity of the $\mathrm{Mg}^{2+}$ stresses the importance of studying the critical $\mathrm{F}^{-}-\mathrm{Ca}^{2+}$ and the $\mathrm{F}^{-}-\mathrm{Mg}^{2+}$ ratios in the groundwater of the hard water terrains on which the population with CKDu lives.

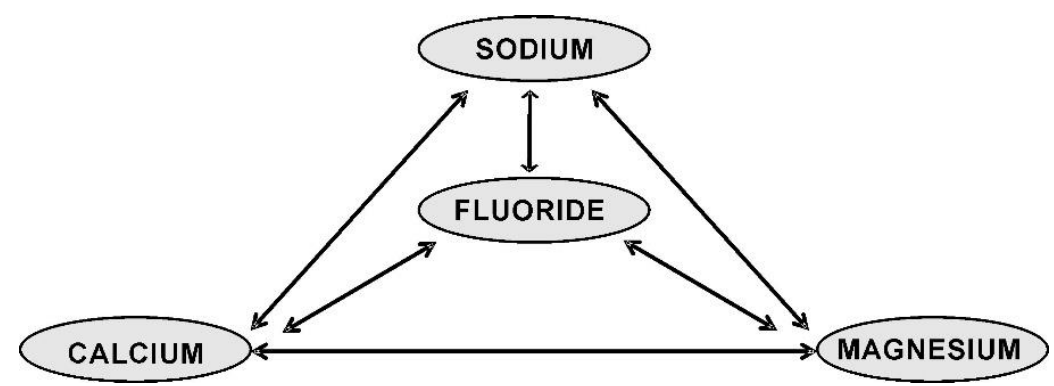

Figure 3: Antagonistic relationship between of $\mathrm{Ca}, \mathrm{Mg}, \mathrm{Na}$ and fluoride 
The effects of $\mathrm{Ca}^{2+}, \mathrm{Mg}^{2+}$, and $\mathrm{F}^{-}$supplementation on tissue mineralization in $\mathrm{Ca}-\mathrm{Mg}$ deficient rats had been studied and it has been noted that the toxic effect of fluoride plays a key role in $\mathrm{Mg}$ deficiency and that the kidneys are the probable place for $\mathrm{Mg}-\mathrm{F}$ interaction (Ericsson $\mathrm{et}$ al., 1986). They showed that $\mathrm{F}^{-}$clearly interferes with the biological activity of the $\mathrm{Mg}^{2+}$. Since hard water contains both $\mathrm{Ca}^{2+}$ and $\mathrm{Mg}^{2+}$ though in different amounts, their ratios will clearly have an impact on their distribution in tissues. In areas such as the dry zone of Sri Lanka, where the farming community is at most risk from the CKD of unknown origin, diet clearly plays a major role. It may be expected that, due to the poor diet, the intake of elements from water may also have significant physiological effects. The biochemical antagonism between $\mathrm{Ca}^{2+}$ and $\mathrm{Mg}^{2+}$ is known and there could be mutual dislodging from cells. In interactions of $\mathrm{F}^{-}$with $\mathrm{Ca}^{2+}$ and $\mathrm{Mg}^{2+}$, it is the $\mathrm{Ca}$ ions rather than $\mathrm{Mg}$ ions that intensify mineral- ization. Calcium accumulation is much more pronounced in the kidneys than in the heart or aorta but both $\mathrm{Mg}$ and fluoride have inhibitory effects. It has been found that moderately high chronic doses of fluoride prevent renal accumulation while higher acute doses increase calcinosis (Luoma et al., 1983; Suketa et al., 1977). The dual role of fluoride as a cytotoxic and cytoprotective agent has to be taken into serious consideration when optimum levels of fluoride are recommended in health issues. In the case of the CKDu in Sri Lanka, most researchers ignore this fact and attempt to correlate total water fluoride values with disease prevalence thereby leading to erroneous conclusions. Renal fluorosis and nephrocalcinosis therefore, becomes a possibility in areas where the groundwater has $\mathrm{Ca}^{2+}, \mathrm{Mg}^{2+}$, $\mathrm{F}^{-}$, and $\mathrm{PO}_{4}{ }^{3-}$ in abundance such as in arid regions of tropical regions where phosphate fertilizers are also used in abundance. Although calcification is mainly extracellular, intracellular calcification has been reported and may contribute to pathologic calcification of soft tissues (Azari et al., 2008). The kidneys could therefore be such a location (figure 2). As shown in figure $3, \mathrm{Ca}^{2+}$ and $\mathrm{Mg}^{2+}$ show interact with each other, calcium being the dominant ion for biomineralization. It combines with fluoride and phosphate to produce nanocrystals of fluoroapatite in the soft issues in the kidney, notably in the tubules which could cause clogging. This is mitigated by magnesium and fluoride, depending strictly on the dose.
Azari et al. (2008) experimentally found that hydroxyapatite crystals nucleate within intracellular membrane-bounded compartments. The discussion thus far emphasizes the extreme importance of the critical ratios of $\mathrm{F}^{-}, \mathrm{Ca}^{2+}, \mathrm{Mg}^{2+}$ and $\mathrm{Na}^{+}$that activate chronic kidney diseases not related to diabetes, hypertension and any other known factors. The fine dividing line between cytotoxicity and cytoprotectivity of fluoride depends strongly on the effect of the abovementioned ions of the ingested water on $\mathrm{F}^{-}$ metabolism (Chandrajith et al., 2011b). The unique feature of fluoride as both a cytotoxic and cytoprotective agent was highlighted by Chouhan and Flora (2008) in their study on the effects of fluoride on the tissue oxidative stress and apoptosis in rats. They noted that fluoride is biologically active even in lower concentrations and that at low levels it exerts more deleterious effects while at higher concentrations the toxic effects are less pronounced. The dose and concentration dependency is once again emphasized. High fluoride, hardness and salinity prevalent in the disease stricken areas of the dry zone of Sri Lanka therefore appear to be contributory factors. It should be noted that areas below irrigation schemes, tanks and reservoirs where water is impounded, as seen in many parts of the dry zone of Sri Lanka, are clearly sodic with the consequent increase of $\mathrm{F}^{-}$and $\mathrm{Ca}^{2+}$. These areas are best known for the high incidence of CKDu. In such areas, $\mathrm{Mg}$ could play a protective role. It was also reported that there was a significant reduction of fluorosis in $\mathrm{Mg}$ fed animals presumably due to a decrease in the intestinal absorption of fluoride (Chouhan and Flora, 2008; Khandare et al., 2011). A noteworthy observation is that patients with CKD have a high prevalence of vascular calcification and cardiovascular disease is the leading cause of death in CKD populations (Massy and Drüeke, 2012). Observational studies had shown that low serum $\mathrm{Mg}$ may be an independent risk factor for premature death in CKD patients and patients with mildly elevated serum levels could have a better chance of survival over those with lower $\mathrm{Mg}$ levels. It has been suggested that $\mathrm{Mg}$ supplementation might be useful in reducing the progression of atherosclerosis in chronic dialysis patients (Turgut et al., 2008). 
Table 1: Summary statistics of some chemical parameters in drinking water wells from CKDu and Non-CKDu regions of Sri Lanka.

\begin{tabular}{|c|c|c|c|c|c|c|c|c|}
\hline Area & $\begin{array}{l}\text { CKDu } \\
\text { Status }\end{array}$ & $\begin{array}{l}\text { No. of } \\
\text { Samples }\end{array}$ & & Hardness & $\mathrm{F}^{-}$ & $\mathrm{Na}^{+}$ & $\mathrm{Ca}^{+2}$ & $\mathrm{Mg}^{+2}$ \\
\hline \multirow[t]{3}{*}{ Giradurukotte } & \multirow[t]{3}{*}{ Endemic } & \multirow[t]{3}{*}{46} & $\min$ & 47 & 0.02 & 1.54 & 1.02 & 2.26 \\
\hline & & & $\max$ & 1921 & 2.14 & 108 & 37.1 & 79.6 \\
\hline & & & Avg & 226 & 0.64 & 22.8 & 13.8 & 19 \\
\hline \multirow[t]{3}{*}{ Nikawewa } & \multirow[t]{3}{*}{ Endemic } & \multirow[t]{3}{*}{39} & $\min$ & 122 & 0.02 & 15.2 & 2.38 & 0.98 \\
\hline & & & $\max$ & 1380 & 5.3 & 540 & 256 & 313 \\
\hline & & & Avg & 426 & 1.21 & 135 & 40.3 & 54.6 \\
\hline \multirow[t]{3}{*}{ Medawchchiya } & \multirow[t]{3}{*}{ Endemic } & \multirow[t]{3}{*}{10} & $\min$ & 208 & 0.52 & 8.02 & 13.5 & 11.4 \\
\hline & & & $\max$ & 676 & 4.9 & 80.7 & 53.5 & 785 \\
\hline & & & Avg & 324 & 1.42 & 47.7 & 33.3 & 98 \\
\hline \multirow{3}{*}{ Padaviya } & \multirow[t]{3}{*}{ Endemic } & \multirow[t]{3}{*}{34} & $\min$ & 80 & 0.02 & 2.09 & 2.35 & 2.08 \\
\hline & & & $\max$ & 816 & 1.33 & 188 & 113 & 41.6 \\
\hline & & & Avg & 454 & 0.62 & 58.3 & 35 & 20.1 \\
\hline \multirow[t]{3}{*}{ Vaunniya } & \multirow[t]{3}{*}{ Endemic } & \multirow[t]{3}{*}{18} & $\min$ & 88 & 0.23 & 8.50 & 4.6 & 0.67 \\
\hline & & & $\max$ & 352 & 1.27 & 183 & 32.3 & 33.5 \\
\hline & & & Avg & 185 & 0.71 & 48.5 & 12.8 & 11.9 \\
\hline \multirow[t]{3}{*}{ Vaunniya } & \multirow{3}{*}{$\begin{array}{l}\text { Non- } \\
\text { Endemic }\end{array}$} & \multirow[t]{3}{*}{14} & $\min$ & 120 & 0.38 & 8.66 & 1.6 & 0.73 \\
\hline & & & $\max$ & 556 & 1.37 & 209 & 69 & 51.6 \\
\hline & & & Avg & 356 & 0.97 & 92.6 & 30.4 & 26.2 \\
\hline \multirow[t]{3}{*}{ Huruluwewa } & \multirow{3}{*}{$\begin{array}{l}\text { Non- } \\
\text { endemic }\end{array}$} & \multirow[t]{3}{*}{29} & $\min$ & 96 & 0.02 & 38.5 & 3.57 & 9.63 \\
\hline & & & $\max$ & 590 & 1.68 & 1910 & 58 & 1280 \\
\hline & & & Avg & 285 & 0.72 & 561 & 29.6 & 189 \\
\hline \multirow[t]{3}{*}{ Wellawaya } & \multirow{3}{*}{$\begin{array}{l}\text { Non- } \\
\text { endemic }\end{array}$} & \multirow[t]{3}{*}{38} & $\min$ & 140 & 0.80 & 19.2 & 16.0 & 10.6 \\
\hline & & & $\max$ & 580 & 7.0 & 101 & 110 & 94.7 \\
\hline & & & Avg & 280 & 2.31 & 48.7 & 49.2 & 38.4 \\
\hline
\end{tabular}

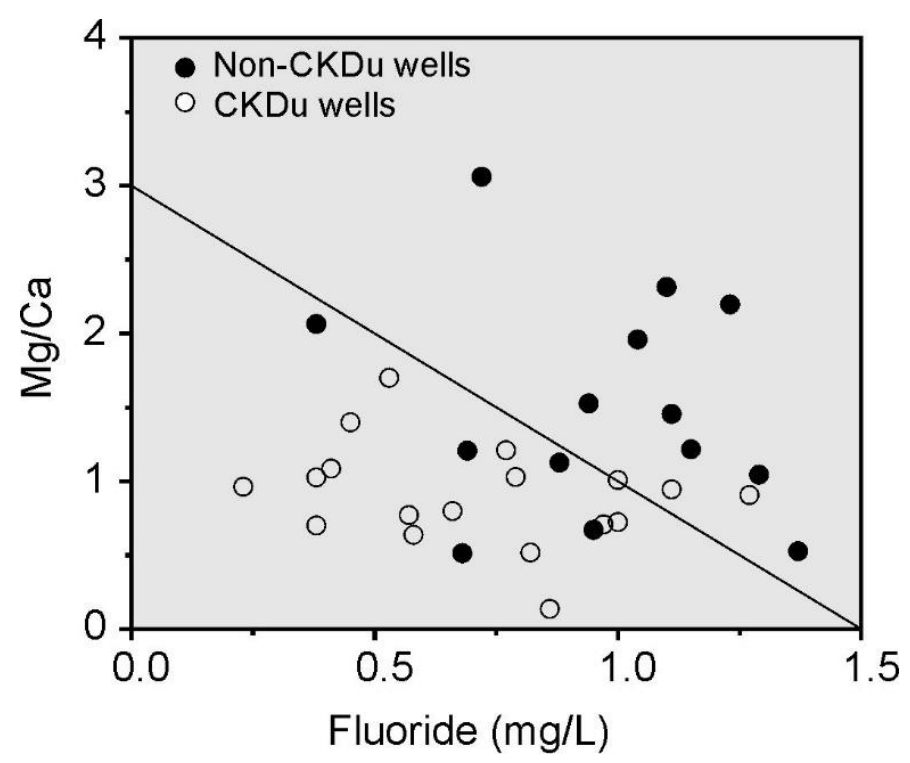

Figure 4: Discrimination between fluoride and $\mathrm{Mg} 2+/ \mathrm{Ca} 2+$ ratio in drinking water wells used by $\mathrm{CKDu}$ and non-CKDu people in Vavuniya, Sri Lanka.

\section{MAGNESIUM DEFICIENCY AS A RISK FACTOR FOR CKDu}

During the last few years, many studies had considered drinking water geochemistry as a causative factor for CKDu in the dry zone of Sri Lanka. Some of these investigations showed a clear difference in $\mathrm{Na}, \mathrm{Ca}$ and fluoride activities in drinking water between affected and nonaffected regions (Chandrajith et al., 2011a; Chandrajith et al., 2011b; Dharma-Wardana et $a l ., 2015)$. It is evident that elevated fluoride in drinking water along with high Ca-hardness could be a possible cause for $\mathrm{CKDu}$ since the 
total hardness is always high in most of the dry zone regions of Sri Lanka (table 1). It is also seen that $\mathrm{Mg}^{2+}$ is higher in non-CKDu regions compared to the endemic regions. A recent study carried out in a $\mathrm{CKDu}$ prevalent village in Vavuniya in which the water samples were collected from wells used by families with $\mathrm{CKDu}$ patients and healthy families (Thilakerathne, 2012), indicated that the groundwater hardness in the study village varied from 88 to $352 \mathrm{mg} / \mathrm{L}$ in $\mathrm{CKDu}$ wells, while in non-CKDu wells were 120 to $556 \mathrm{mg} / \mathrm{L}$. Therefore high hardness is common in the areas under investigation. However, the mean $\mathrm{Mg}^{2+}$ in drinking water wells of $\mathrm{CKDu}$ and non-CKDu groups were 12 and $26 \mathrm{mg} / \mathrm{L}$. respectively with the fluoride concentration in all studied samples ranging from 0.23 to $1.37 \mathrm{mg} / \mathrm{L}$ with a mean value of $0.82 \mathrm{mg} / \mathrm{L}$. It was observed that $72 \%$ of the samples had fluoride above $0.6 \mathrm{mg} / \mathrm{L}$ recommended for tropical countries (WHO, 2004). The mean values of fluoride in CKD region and non-CKD regions were 0.71 and 0.97 $\mathrm{mg} / \mathrm{L}$, respectively and are higher than that of the WHO recommended levels. A clear discrimination between the fluoride and $\mathrm{Ca} / \mathrm{Mg}$ ratios can be observed for the $\mathrm{CKDu}$ and non$\mathrm{CKDu}$ drinking water wells (figure 4). Although higher hardness $(\mathrm{Ca}+\mathrm{Mg})$ and fluoride is a common factor in most of the dry zone of Sri Lanka (Chandrajith et al., 2012), the Mg-factor is extremely important in the case of CKDu foci in the dry zone of Sri Lanka. While calcium has been given very high prominence, magnesium has been grossly underestimated even though it plays a major role in cardioprotectivity and its calcium antagonistic properties. The complex biochemical interaction among $\mathrm{Ca}, \mathrm{Mg}, \mathrm{Na}$ and fluoride ions is once again highlighted. The variation of the $\mathrm{Ca} / \mathrm{Mg}$ ratio in the groundwater of a region and its possible link to the prevalence of CKDu needs to be studied in depth.

Xiong et al. (2007) indicated that high levels of drinking water fluoride can increase the levels of two kidney damage markers, Nacetylglucosaminidase (NAG) and $\gamma$-glutamyl transferase $(\gamma-\mathrm{GT})$ in urine in children. The CKDu in dry zone of Sri Lanka is known as a slow progressing disease and the investigations on histopathology of kidney of patients with $\mathrm{CKDu}$ indicated a tubulointerstitial disease present mainly as focal to diffuse fibrosis. This is accompanied by varying degrees of sclerotic vascular lesions resulting in high frequency of glomerular sclerosis and collapse more indicative of a toxic etiology (Nanayakkara et al., 2014). Therefore initial damage can occur even in the younger cohorts who drink water with high hardness, high fluoride in which $\mathrm{Ca}$ is the dominant ion for the hardness.

\section{CONCLUSION}

Groundwater geochemistry plays a major role in the etiology of some diseases such as dental and skeletal fluorosis, chronic kidney disease among others in arid regions of tropical countries. Fluoride, when abundant in such terrains acts a geochemical carrier and as a strong marker for most heavy metals such as $\mathrm{Cd}, \mathrm{Hg}, \mathrm{Pb}$ and metalloids such as As, generally implicated for chronic kidney diseases not attributed to diabetes and hypertension. The very high reactivity of the fluoride ion enables many insoluble environmental toxicants to enter pathways that may ultimately enter the human body causing the disease. Magnesium, commonly present in hard water in the tropical arid regions plays a protective role against the disease while fluoride shows both cytoprotectivity and cytoxicity depending on the dose, bioavailability and other factors affecting its biochemistry. Climate change within the last two decades has brought about marked geochemical changes in the groundwater of arid regions prone to kidney diseases, with subtle changes in the ratios involving $\mathrm{Ca}, \mathrm{Mg}, \mathrm{F}$, and phosphate ions. Consideration of Ca-hardness, Mg-hardness and temporary hardness is more important than total hardness when correlating disease patterns with geochemical parameters. Fluoride, by virtue of its extreme reactivity acts as a potent geochemical carrier for a large number of chemical species that are often classified as nephrotoxic as exemplified by $\mathrm{Cd}, \mathrm{Pb}$ and $\mathrm{Hg}$.

\section{ACKNOWLEDGEMENTS}

This work was carried out as a part of a research project on chronic kidney disease, funded by the National Research Council (NRC), Sri Lanka through Grant No. TO 14-05 offered to RC.

\section{REFERENCES}

Athuraliya, N.T.C., Abeysekera, T.D.J., Amerasinghe, P.H., Kumarasiri, R., Bandara, P. and Karunaratne, U. (2011). Uncertain etiologies of proteinuric-chronic kidney disease in rural Sri Lanka. Kidney international 80: 1212-1221.

Azari, F., Vali, H., Guerquin-Kern, J.L., Wu, T.D., Croisy, A. and Sears, S.K. (2008). Intracellular 
precipitation of hydroxyapatite mineral and implications for pathologic calcification. Journal of structural biology 162: 468-479.

Barbier, O., Arreola-Mendoza, L. and Del Razo, L.M. (2010). Molecular mechanisms of fluoride toxicity. Chemico-biological interactions $\mathbf{1 8 8}$ 319-333.

Bober, J., Kwiatkowska, E., Kedzierska, K., Olszewska, M., Stachowska, E. and Ciechanowski, K. (2006). Fluoride aggravation of oxidative stress in patients with chronic renal failure. Fluoride 39: 302.

Chandrajith, R., Nanayakkara, S., Itai, K., Aturaliya, T.N.C., Dissanayake and C.B., Abeysekera, T. Harada, K., Watanabe, T. and Koizumi, A. (2011a). Chronic kidney diseases of uncertain etiology (CKDue) in Sri Lanka: geographic distribution and environmental implications. Environmental Geochemistry and Health 33: 267-278.

Chandrajith, R., Dissanayake, C.B., Ariyarathna, T., Herath, H.M.J.M.K. and Padmasiri, J.P. (2011b) Dose-dependent $\mathrm{Na}$ and $\mathrm{Ca}$ in fluoride-rich drinking water-Another major cause of chronic renal failure in tropical arid regions. Science of the Total Environment 409: 671-675.

Chandrajith, R., Padmasiri, J.P., Dissanayake, C.B. and Prematilake, K.M. (2012). Spatial distribution of fluoride in groundwater of Sri Lanka. Journal of the National Science Foundation of Sri Lanka 40: 303-309.

Chattopadhyay, A., Podder, S., Agarwal, S. and Bhattacharya, S. (2011). Fluoride-induced histopathology and synthesis of stress protein in liver and kidney of mice. Archives of toxicology 85: 327-335.

Chouhan, S. and Flora, S.J.S. (2008). Effects of fluoride on the tissue oxidative stress and apoptosis in rats: biochemical assays supported by IR spectroscopy data. Toxicology 254: 61-67.

Cittanova, M-L., Lelongt, B., Verpont, M-C., Geniteau- Legendre, M., Wahbe, M.D.F., Prie, M.D.D. Coriat, M.D.P. and Ronco, M.D.P.M. (1996). Fluoride ion toxicity in human kidney collecting duct cells. The Journal of the American Society of Anesthesiologists 84: 428-435.

Dharma-Wardana, M.W.C., Amarasiri, S.L., Dharmawardene, N. and Panabokke, C.R. (2015). Chronic kidney disease of unknown aetiology and ground-water ionicity: study based on Sri Lanka. Environmental Geochemistry and Health 37: 221-231.

Dissanayake, C.B. (2005). Water quality in the dry zone of Sri Lanka-some interesting health aspects. Journal of the National Science Foundation of Sri Lanka 33(3): 161-168.

Dissanayake, C.B. and Chandrajith, R. (1999). Medical geochemistry of tropical environments. Earth-Science Reviews 47: 219-258.
Dissanayake, C.B and Chandrajith, R. (2007). Medical geology in tropical countries with special reference to Sri Lanka. Environmental Geochemistry and Health 29: 155-162.

Dissanayake, C.B and Weerasooriya, S.V.R. (1985). hydrogeochemical atlas of Sri Lanka: Natural Resources, Energy \& Science Authority of Sri Lanka. 103.

El Nahas, A.M. and Bello, A.K. (2005).Chronic kidney disease: the global challenge. Lancet (London, England) 365: 331-340.

Ericsson, Y., Luoma, H. and Ekbergm O. (1986). Effects of calcium, fluoride and magnesium supplementations on tissue mineralization in calcium-and magnesium-deficient rats. The Journal of nutrition 116: 1018-1027.

Gröber, U. (2007). Antihypertensives and magnesium - Update. Trace Elements \& Electrolytes 26: 1516.

Harinarayan, C.V., Kochupillai, N., Madhu, S.V., Gupta, N. and Meunier, P.J. (2006). Fluorotoxic metabolic bone disease: an osteo-renal syndrome caused by excess fluoride ingestion in the tropics. Bone 39: 907-914.

Jacks, G., Bhattacharya, P., Chaudhary, V. and Singh, K.P. (2005). Controls on the genesis of some high-fluoride groundwaters in India. Applied Geochemistry 20: 221-228.

Jayasumana, M.A.C.S., Paranagama, P.A., Amarasinghe, M.D., Wijewardane, K.M.R.C., Dahanayake, K.S., Fonseka, S.I.,Rajakaruna, K.D.L.M.P., Mahamithawa, A.M.P., Samarasinghe, U.D. and Senanayake, V.K. (2013). Possible link of Chronic arsenic toxicity with Chronic Kidney Disease of unknown etiology in Sri Lanka. Journal of Natural Sciences Research 3: 64-73.

Jayatilake, N., Mendis, S., Maheepala, P., Mehta, F.R. (2013). Chronic kidney disease of uncertain aetiology: prevalence and causative factors in a developing country. BMC Nephrology 14: 180.

Jiang, L., He, P., Chen, J., Liu, Y., Liu, D., Qin, G. andTan, N. (2016). Magnesium Levels in Drinking Water and Coronary Heart Disease Mortality Risk: A Meta-Analysis. Nutrients 8: 5.

Khandare, A., Kumar, U. and Raoc, S. (2011). Magnesium hydroxide for protection against fluoride toxicity in rabbits. Fluoride 44(1):21-26

Knezović, N.J., Memić, M., Mabić, M., Huremović, J. and Mikulić, I. (2011). Correlation between water hardness and cardiovascular diseases in Mostar city, Bosnia and Herzegovina. Journal of Water and Health 12: 817-823.

Kousa, A. (2013). Magnesium and Calcium in Drinking Water and Heart Diseases. Reference Module in Earth Systems and Environmental Sciences 535-544.

Leurs, L.J., Schouten, L.J., Mons, M.N., Goldbohm, R.A. and Van Den Brandt, P.A. (2010). Relationship between tap water hardness, magnesium, and 
calcium concentration and mortality due to ischemic heart disease or stroke in the Netherlands. Environmental Health Perspectives 118: 414-420.

Luoma, H., Koskinen, M., Tuomisto, J. and Collan, Y. (1983). Reduction of the lethality and the nephron-calcinotic effect of single fluoride doses by magnesium in rats. Magnesium 3: 81-87.

Massy, Z.A. and Drüeke, T.B. (2012). Magnesium and outcomes in patients with chronic kidney disease: focus on vascular calcification, atherosclerosis and survival. Clinical kidney journal 5: 152-161.

Nanayakkara, S., Senevirathna, S., Abeysekera, T., Chandrajith, R., Ratnatunga, N., Gunarathne, L., Yan, J., Hitomi, T., Muso, E., Komiya, T., Harada, K.H., Liu, W., Kobayashi, H., Okuda, H., Sawatari, H., Matsuda, F., Yamada, R., Watanabe, T., Miyataka, H., Himeno, S. and Koizumi, A. (2014). An integrative study of the genetic, social and environmental determinants of chronic kidney disease characterized by tubulointerstitial damages in the North Central Region of Sri Lanka. Journal of occupational health 56: 28-38.

Podder, S., Chattopadhyay, A. and Bhattacharya, S. (2011). Reduction in fluoride- induced genotoxicity in mouse bone marrow cells after substituting high fluoride- containing water with safe drinking water. Journal of Applied Toxicology 31: 703-705.

Strochkova, L.S. and Zhavoronkov, A.A. (1983). Fluoride as an activator of enzymatic systems. Fluoride 16: 181-186.

Suketa, Y., Mikami, E. and Hayashi, M. (1977). Changes in calcium and magnesium in the kidneys of rats intoxicated with a single large dose of fluoride. Toxicology and applied pharmacology 39: 313-319.

Thilakerathne, H.M.A.G.B. (2012). Hydrogeochemical aetiology of unidentified Chronic
Kidney Disease (CKDu) - a study from Mahamilakulam, Vunniya. Postgraduate Institute of Science. M.Sc. University of Peradeniya, Peradeniya.

Turgut, F., Kanbay, M., Metin, M.R., Uz, E., Akcay, A. and Covic, A. (2008). Magnesium supplementation helps to improve carotid intima media thickness in patients on hemodialysis. International urology and nephrology 40: 10751082.

WHO. (2004). World Health OrganizationGuidelines for drinking-water quality: recommendations. Vol 1: World Health Organization.

Wimalawansa, S.J. (2016). The role of ions, heavy metals, fluoride, and agrochemicals: critical evaluation of potential aetiological factors of chronic kidney disease of multifactorial origin (CKDmfo/CKDu) and recommendations for its eradication. Environmental Geochemistry and Health 38: 639-678.

Xiong, X., Liu, J., He, W., Xia, T., He, P., Chen, X., Yang, K. and Wang, A. (2007). Dose-effect relationship between drinking water fluoride levels and damage to liver and kidney functions in children. Environmental Research 103: 112116.

Yang, Y., Deng, Y. and Wang, Y. (2016). Major geogenic factors controlling geographical clustering of urolithiasis in China. Science of the Total Environment 571: 1164-1171.

Zager, R.A. and Iwata, M. (1997). Inorganic fluoride. Divergent effects on human proximal tubular cell viability. The American journal of pathology 150: 735.

Zhang, J., Song, J., Zhang, J., Chen, X., Zhou, M., Cheng, G., Guang Cheng, G. and Xie, X. (2013). Combined effects of fluoride and cadmium on liver and kidney function in male rats. Biological trace element research 155: 396-402. 